\title{
The Dynamics of Hours Worked and Technology*
}

\author{
Cristiano Cantore \\ University of Surrey ${ }^{\dagger}$
}

\author{
Filippo Ferroni \\ Chicago FED, University of Surrey ${ }^{\ddagger}$
}

\author{
Miguel A. León-Ledesma \\ University of Kent ${ }^{\S}$
}

May 10, 2017

\begin{abstract}
The response of hours worked to technology shocks in the postwar US economy has increased over time. We offer a structural interpretation of this important time-varying macroeconomic moment. The time varying patterns captured by a structural VAR are consistent with those obtained from a parsimonious RBC model with a less than unitary elasticity of substitution between capital and labor $(\sigma)$. The observed changes in the response of hours are attributable to increases in the magnitude of the degree of capital-labor substitution. Finally, we conjecture that the observed time-variation in $\sigma$ is related to changes in the skill composition of the work force and biases in technological change.
\end{abstract}

JEL classification: E32, E37, C53

Keywords: Real Business Cycles models, Constant Elasticity of Substitution production function, Hours worked, technology shocks.

\footnotetext{
*An earlier version of this paper was entitled 'Interpreting the Hours-Technology time-varying relationship'. We thank seminar participants at the University of California San Diego, Surrey, Kent, Saint Andrews, Porto, Cardiff, Banque de France, Banco de España, ECB, Reserve Bank of New Zealand, the 3rd Carlo Giannini Conference at the Bank of Italy, Structural Change and Macroeconomic Performance workshop at Universita' di Cagliari, the $17^{\text {th }}$ International Conference on Computing in Economics and Finance and the Mid West Macro meeting. We thank Yongsung Chang, Sergio Destefanis, Patrick Feve, Francesco Nucci, Valerie Ramey and two anonymous referees for excellent discussions and Vasco Carvalho, Peter McAdam, Fabio Canova, Christian Hellwig and Alessio Moro for helpful exchanges. Cristiano Cantore acknowledges financial support from the Banco de España, where part of this research was conducted.

${ }^{\dagger}$ Department of Economics, University of Surrey, Surrey GU2 7XH UK (e-mail:c.cantore@surrey.ac.uk)

${ }_{\ddagger}^{\ddagger}$ The views in this paper are solely the responsibility of the authors and should not be interpreted as reflecting the views of the Federal Reserve Bank of Chicago or any other person associated with the Federal Reserve System (e-mail:fferroni@frbchi.org).

${ }^{\S}$ School of Economics and Macroeconomics, Growth and History Centre (MaGHiC), University of Kent, Canterbury, Kent, CT27NP UK (e-mail:M.A.Leon-Ledesma@kent.ac.uk).
} 


\section{INTRODUCTION}

One of the most controversial issues in business cycle theory regards the impact of technology shocks on hours worked. From a theoretical standpoint, the sign and size of the responses of hours to a positive technology shock was used as evidence to distinguish between theories, i.e. the RBC and the New Keynesian paradigms, see Galí (1999). This particular impulse response, it was argued, could tells us whether we live in a world where output is largely driven by supply shocks or a Keynesian world in which output is largely demand-determined over the short-run due to price (and possibly wage) rigidities. If it is the former, then a positive technology shock induces people to work more. If it is the latter, then demand remains unchanged in the short-run and firms would lay off workers. As a consequence, a large empirical literature developed to identify technology shocks and analyze the response of hours in order to shed light on the empirical validity of competing theories of business cycle fluctuations. However, it relied on two crucial assumptions: (i) that the impact of technology shocks does not change over time ${ }^{1}$ and (ii) that the impact of technology shocks on hours crucially depends on the demand side of the economy via the speed of price adjustments.

In this paper, we contribute to the literature by relaxing both assumptions. We first present further evidence that the response of hours to technology shocks has changed from negative to positive for the US economy between the post-WW2 period and the advent of the Great Recession. We then present an alternative structural explanation for the change in this impulse response that relies solely on the supply side of the economy: we argue that this observed change is due to changes in the degree of input complementarity in production. We propose and estimate parsimonious RBC model with a Constant Elasticity of Substitution production function and show that the elasticity of capital-labor substitution increased substantially throughout the sample period. We then test empirically the validity of our explanation to replicate the time variation in the response of hours to technology shocks.

Previous studies (e.g. Galí and Gambetti 2009) show that the response of hours has substantially changed over time, i.e. it was typically negative at the beginning of the post-war sample and it turned positive or zero towards the end. ${ }^{2}$ However, while they propose some explanations for these changes, the empirical framework they adopt, by construction, does not allow for structural interpretations of this phenomenon. One of our contributions is to provide a plausible explanation.

We start off presenting further evidence and robustness on the time varying relationship between hours and technology shocks by estimating a SVAR on overlapping windows of fixed length. Regardless of the amplitude of the windows, the filter used on hours, and the measure of hours worked,

\footnotetext{
${ }^{1}$ This assumption is difficult to entertain given the number of structural changes undergone by the US economy from the postwar era until recent years.

${ }^{2}$ See also Stiroh (2009) for an analysis of changing unconditional correlations between productivity growth and hours growth.
} 
we find that the response of hours worked has increased over the sample. The response is negative at the beginning of the sample and turns positive or zero towards the end in line with the findings of Galí and Gambetti (2009). Moreover, we complement the VAR analysis with a reduced form framework where we study the correlation between hours and an empirical measure of TFP growth over the same overlapping windows. The estimated regression coefficients have a qualitative pattern comparable to the conditional correlation obtained from the SVAR. We also argue that this is one of the few robust changing moments in US macroeconomic time series on productivity, hours, and output that has a direct interpretation in terms of model shocks.

We then interpret such patterns using a parsimonious structural model. The model is a standard $\mathrm{RBC}$ where the production technology combines labor and capital with a constant - but not necessarily unitary - elasticity of substitution. Within this framework, in line with Cantore, León-Ledesma, McAdam and Willman (2014), the response of hours to a technology shock depends crucially on the value of the elasticity of capital-labor substitution. When capital and labor are strongly gross complements, as recent empirical evidence suggests, ${ }^{3}$ an increase in labor efficiency leads to a reduction in wages and hours until firms have enough capital to combine with labor. ${ }^{4}$ Thus, the demand for labor falls in the short-run in response to a technology shock, but not for reasons related to price and wage rigidities. When we bridge the model to the same overlapping sub-samples of the SVAR, we find that the response of hours worked obtained with the RBC model mimics fairly well those from the SVAR. ${ }^{5}$ The driving factor behind the increase in the conditional correlation of hours is an increase in the estimate of the elasticity of substitution over time from a value close to 0.2 in early samples to 0.8 towards the end of the period considered.

We then carry out a series of empirical and theoretical robustness exercises. We start on the empirical side by noting the large increase in our structural estimates, we therefore estimate the elasticity of substitution in rolling sub-samples using the (static) normalised system method of LeónLedesma, McAdam and Willman (2010). We also observe a substantial increase of similar (albeit smaller) magnitude that supports our previous estimates. On the theoretical side, we compare our structural interpretation to alternative competing explanations. Since there are several potential structural explanations available in the literature for the negative response of hours in the full sample then changes in the parameters of these models could offer competing explanations for the observed change in the response of hours. When we compare our model performance to those alternatives, we find that these competing explanations are unable to match the empirical findings. We conclude

\footnotetext{
${ }^{3}$ See León-Ledesma, McAdam and Willman (2015) and Klump, McAdam and Willman (2012) for a survey.

${ }^{4}$ See also Francis and Ramey (2005) and Wang and Wen (2011).

${ }^{5}$ In the online Appendix, we perform a reverse engineering exercise à la Erceg, Guerrieri and Gust (2005) and Chari, Kehoe and McGrattan (2008), comparing the responses of hours in a SVAR model obtained using data generated by the estimated theoretical model to those obtained using actual data. The results indicate that both sets of responses are reasonably similar.
} 
that our structural model offers a plausible and robust explanation for the observed changes in the response of hours. This is important given the increased focus in the literature on explaining the changing macroeconomic moments observed in the US data (see, e.g. Fernald and Wang (2016)).

In our model, the observed variation of the elasticity of capital-labor substitution means that it is not a structural parameter in a strict sense. We thus offer an interpretation these changes. We conjecture that changes in the skill composition of the labor force (and biased technical change) could account for the protracted increase in $\sigma$. Since the skill composition of the labor force has deep implications for the elasticity of capital-labor substitution, it can affect the way technology shocks are transmitted into the labor market and hence on aggregate hours worked. Of course, we do not rule out the potential relevance of alternative explanations of changes in the conditional hours-productivity correlations. Frictions and macroeconomic policies can play a relevant role that cannot be undermined. Our paper, however, emphasizes the importance of deeper changes in the skill structure of the US economy as a key driver of this crucial changing macroeconomic correlation.

There is a wide literature related to our paper. On pure measurement grounds, the estimated impact of technology shocks on hours using postwar US data is far from being generally agreed upon and it has been lively debated. Using long run restrictions on a VAR the sign of the response of hours is sensitive to the treatment of hours worked, i.e. if they enter in level or in first difference (see Christiano, Eichenbaum and Vigfusson (2003)). To overcome this ambiguity, researchers switched attention to different identification schemes such as sign, as opposed to zero, restrictions (see Uhlig (2004) and Dedola and Neri (2007)), richer information sets (see Fève and Guay (2010)), alternative ways of measuring technology shocks (see Basu, Fernald and Kimball (2006) and Alexopoulos (2011)), and the use of richer sectoral datasets (see Chang and Hong (2006) and Holly and Petrella (2012)). However, sticking to the original information set and identification scheme of Galí (1999), Canova, Lopez-Salido and Michelacci (2010) and Fernald (2007), amongst others, showed that the results depend dramatically on the treatment of the long run movements of hours. If these are controlled for, with filters or by removing trend breaks, hours decline.

Related literature has also aimed at explaining the changing nature of some key data moments in the US economy regarding output, hours and productivity. Probably the explanation that has received most attention is the well known change in monetary policy at the beginning of the 80 's. ${ }^{6}$ However, this explanation is not free from criticism. For instance, Canova and Gambetti (2009) find little support for the role of monetary policy changes in driving output and inflation dynamics and point towards the potential importance of changes in private sector behavior. We thus compare this explanation with ours and show that the model in Galí et al. (2003) implies counter-factual changes in the the volatility of hours. Nucci and Riggi (2013) attribute changes in the response of

\footnotetext{
${ }^{6}$ See amongst other Clarida, Galí and Gertler (2000), Galí, López-Salido and Vallés (2003) and Cogley and Sargent (2005).
} 
hours to an increase in performance-related pay schemes during the 1980s. Their model, however, can account for a reduction in the negative response of hours to a technology shock but not for a sign switch. Similar considerations apply to models where these changes are attributed to reduced labor market frictions (see Galí and van Rens (2014)). An alternative explanation offered by Lindé (2009) and Rotemberg (2003) relies on changes in the diffusion of technology shocks. Also, Rebei (2014) favours models with investment adjustment costs and consumption habits. We can account for these in our setting but, as mentioned above, find that they did not play a key role in explaining the change in the response of hours. It has to be noted, as will be argued below, that we focus on the response of hours to a productivity shock because: i) unlike other moments, its change is robust to different data definitions and filters and ii) because there is a direct, one-to-one, mapping to theory shocks, unlike in the case of non-technology shocks. ${ }^{7}$

The rest of the paper is organized as follows. Section 2 presents the empirical dynamics of hours and technology and discusses why we focus on their correlation; Section 3 presents briefly the structural model and its time-varying estimation; Section 4 presents the robustness analysis and discusses alternative structural explanations; Section 5 offers possible explanations to rationalize the observed changes in the elasticity of substitution, and section 6 concludes.

\section{The Empirical Dynamics of Hours and Technology}

While there is a large literature documenting the changes in the second moments of various US times series, here we focus on the response of hours worked to a technology shock. To identify the technological process we adopt two strategies. The first approach relies on the production function, which can be represented in its most general form as

$$
Y_{t}=A_{t} F\left(K_{t-1}, Z_{t} H_{t}\right)
$$

where $F(.,$.$) is a constant returns to scale production function, K_{t-1}$ and $H_{t}$ are effective capital and labor input services employed at time $t$ (even allowing for unobservable variations in utilization), $A_{t}$ is a (temporary) displacement to total factor productivity and $Z_{t}$ represents the permanent technological progress. ${ }^{8}$ We can rewrite the latter in terms of the log of output per hours worked (i.e. labor productivity),

$$
p_{t}=\ln \frac{Y_{t}}{H_{t}}=\ln A_{t}+\ln Z_{t}+\ln F\left(\frac{K_{t-1}}{Z_{t} H_{t}}, 1\right) .
$$

\footnotetext{
${ }^{7}$ Many of the data and theoretical robustness analyses carried out in the paper are contained in the extensive online appendix.

${ }^{8}$ With an homogeneous production function of degree one equation (1) is equivalent to

$$
Y_{t}=F\left(Z_{t}^{k} K_{t-1}, Z_{t}^{h} H_{t}\right)
$$

where $Z_{t}^{k}=A_{t}$ and $Z_{t}^{h}=Z_{t} A_{t}$
} 
From economic theory (see Uzawa (1961) and King, Plosser and Rebelo (1988)), we know that the only source of growth consistent with a balanced growth path must be expressible in labor augmenting form. From econometric theory (see Quah (1992)), we know that any time series made up of permanent and transitory shocks is characterized by different spectra for the persistent and temporary component, i.e. at frequency zero (long run) the permanent shock has full power and the transitory null. At any other frequency the two process have non zero power. Thus, we can uniquely identify the labor augmenting technical process from the times series of labor productivity by assuming it to be the only shock having an impact in the long run. This specification was used first by Galí (1999). The second approach to measure the relationship between hours and technology is more empirical and relies on the regression of hours worked on an empirical measure of technology. We adopt the measure of utilization adjusted quarterly TFP growth proposed by Fernald (2014) and based on Basu et al. (2006) as proxy for technology.

Our data ranges from 1948:Q1 until 2009:Q1. ${ }^{9}$ The times series used for the results reported below include output in the non-farm business sector (OUTNFB), which was obtained from the FRED database, and a measure of hours worked constructed by Francis and Ramey (2009). Labor productivity is computed as the ratio between the measure of output and hours, and we take logarithms of both series. For both approaches, we estimate parameters using Bayesian methods assuming flat priors. We estimate both setups on rolling windows of fixed length, starting from the sample [1948:Q2,1978:Q1], and repeating the estimation moving the starting date by one year and stopping at [1979:Q2,2009:Q1]. ${ }^{10}$ In each subsample the growth rate of productivity and hours worked are demeaned.

In the online appendix we discuss in-depth the data construction and show that our results are independent of the measure of hours worked and their transformations. Apart from the Francis and Ramey (2009) measure of hours, we consider the specification of hours used in Galí and Gambetti (2009), Chang, Doh and Schorfheide (2007) as well as Ríos-Rull, Schorfheide, Fuentes-Albero, Kryshko and Santaeulália-Llopis (2012). Importantly, the Francis and Ramey (2009) measure of hours already controls for the low frequency movements in hours induced by demographic and sectoral shifts. All databases display similar patterns. Moreover, beyond robustness to alternative data definitions, we carry out a robustness analysis by extracting different portions of fluctuations from each measure of hours worked. We consider, in turn, the growth rate of hours, where high frequency

\footnotetext{
${ }^{9}$ Our sample stops in 2009 to avoid the end of sample instability generated by the Great Recession and subsequent recovery. However in section 7 of the online appendix we provide the estimates up to 2016Q4 showing that while the Great Recession temporarily blurred the correlation of hours and technology the overall increasing pattern does not revert back to early sample estimates.

${ }^{10}$ We considered also different windows sizes and the results do not change. It is important to stress that smaller windows introduce a large portion of high frequency components (noise) which is typically absorbed by the parameters estimates. This, in turn, makes the time variation of the impulse responses not very smooth and more prone to small sample bias.
} 
fluctuations are emphasized, HP filtered hours with a smoothing parameter of 1600, so that fluctuations larger then 32 quarters are dampened, and quadratic detrended hours whose spectrum contains a significant portions of medium term fluctuations. We show that all the results are insensitive to these transformations with the exception of the first difference case. ${ }^{11}$ We conclude that the time variation in the relationship between hours worked and technology shocks is robust to both data construction and filtering techniques.

\section{$2.1 \quad$ Structural VAR Analysis}

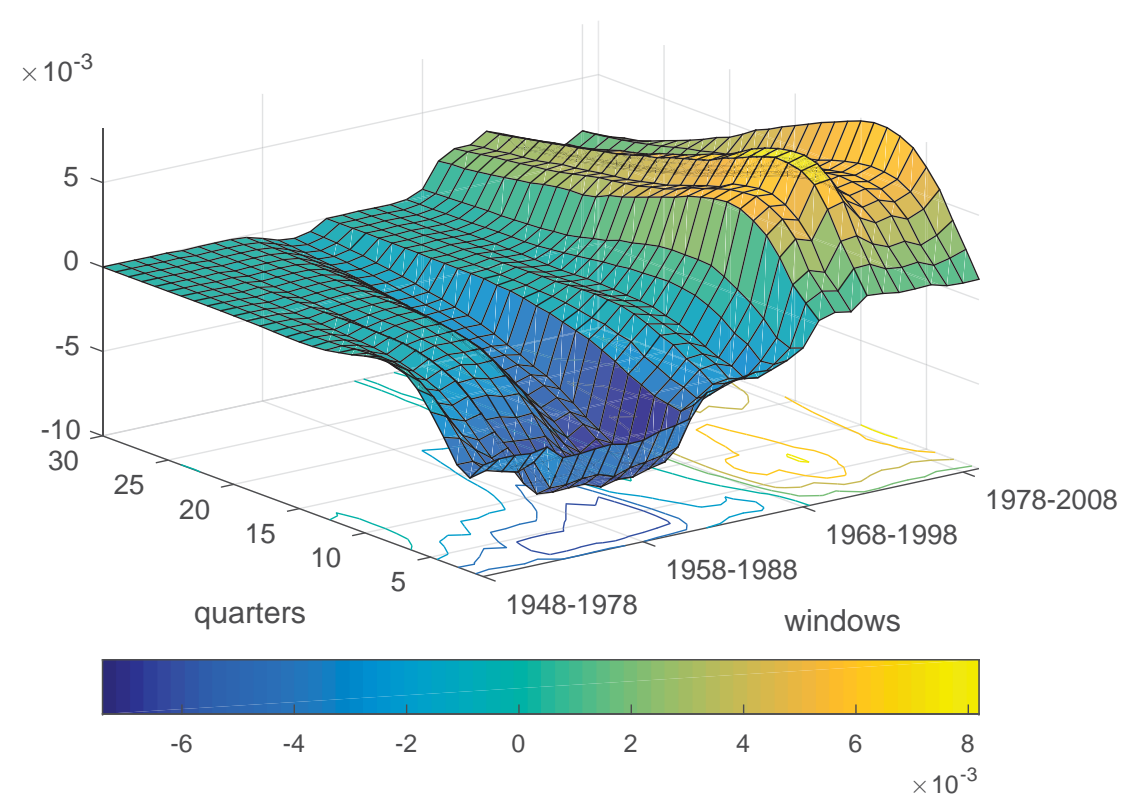

Figure 1: Response of hours worked to a technology shock over overlapping windows, the median response is reported.

Figure 1 plots the response of hours worked to a technology shock in the estimated SVAR with three lags. ${ }^{12}$ The response of hours worked displays significant time variations. In fact, the impact response is negative in early samples, decreases until the mid-1970s, and then increases steadily thereafter. To aid visual analysis, figure 2 reports the impulse responses for selected sub-samples

\footnotetext{
${ }^{11}$ This outcome is not surprising. A first difference filter dampens both long run and business cycles frequencies and tends to overemphasize high frequency fluctuations. The secular change in the conditional correlation of hours and technology has more likely occurred at medium run or business cycle frequencies of the spectrum rather than at noisy frequency. Hence, by taking first differences we downsize the impact of long run and business cycle frequencies, making it difficult to spot time variations. This argument is reinforced if we consider the response of HP filtered hours or quadratic detrended hours, where business cycle frequencies are left unchanged and where we do observe a time varying pattern.

${ }^{12}$ Details on the SVAR representation and estimation are available in section 3 of the online Appendix.
} 


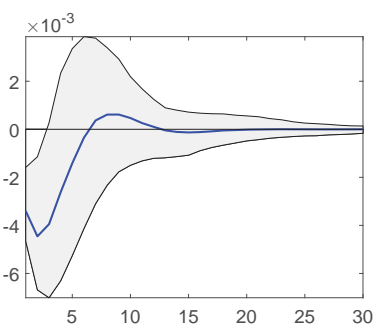

(a) $1948-1978$

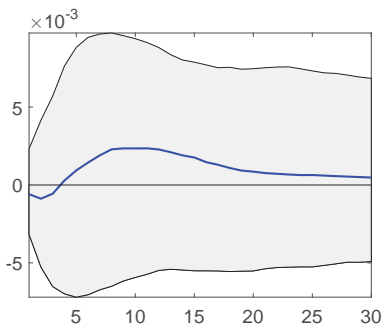

(c) $1968-1998$

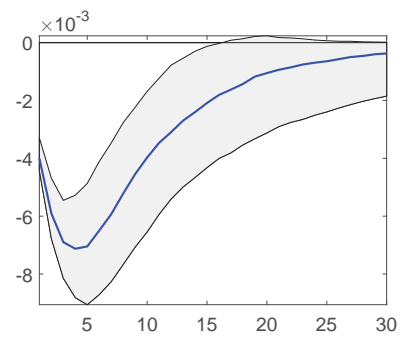

(b) $1958-1988$

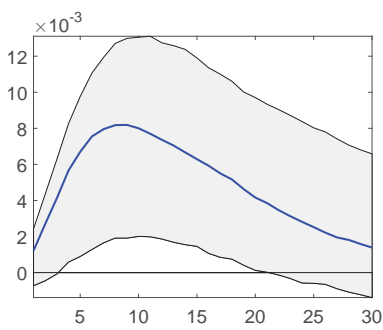

(d) 1979-2009

Figure 2: Response of hours worked to a technology shock for selected sub-samples with $68 \%$ credible sets. The blue line is the median estimated transmission.

with $68 \%$ credible sets. As it clearly stands out, the response of hours worked to an identified technology shock has changed over time. In particular, while it was negative during the 1960s and 1970s on impact, it was negligible during the 1980s, and hours increase following a technology shock if we consider the samples that include entirely the 1990s. This pattern is robust to three alternative specifications. First, we check for omitted variables bias by adding more variables to the VAR. We estimated a four variables VAR with long run restrictions using labor productivity growth, hours worked, inflation, and the real interest rate. The increase in the response of hours remains robust. Second, measuring productivity using the utilization-adjusted measure of TFP by Fernald (2014), we still find the same qualitative picture. Finally, we considered the effect of investment-specific technology shocks using an alternative identification scheme which distinguishes investment-specific and neutral technology shocks following Fisher (2006). Our results, again, were robust to the introduction of the relative price of investment in the VAR.

\subsection{Complementary Empirical Evidence}

We present an alternative but complementary framework to measure the relationship between hours and technology. We consider the following specification

$$
h_{t}=\alpha_{0}+\alpha_{1} t+\beta(L) h_{t}+\delta T F P_{t}+\epsilon_{t}
$$


where $\beta(L)$ is a polynomial in the lag operator and $T F P_{t}$ is a measure of utilization adjusted TFP growth proposed by Fernald (2014). We are interested on the estimates of $\delta$ over overlapping subsamples. Figure 3 reports the estimates of $\widehat{\delta}$ with the $68 \%$ confidence sets (dotted lines) across overlapping windows. Regardless of the number of lags, the estimated response of hours tends to increase over time, moving from negative to zero values.

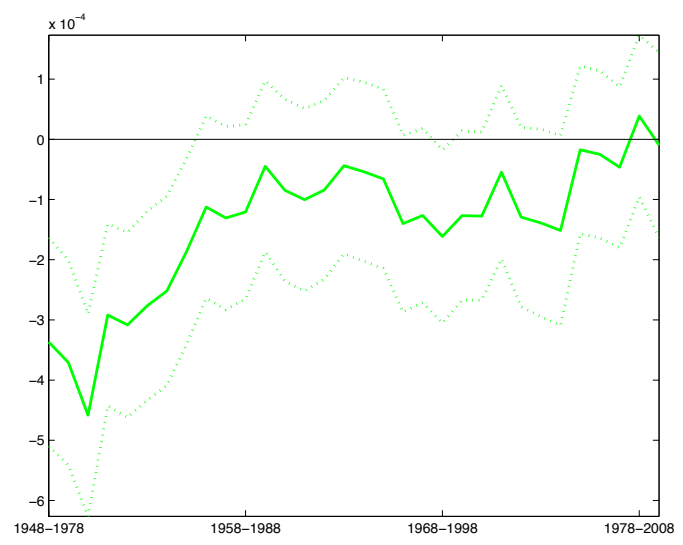

Figure 3: Estimates of $\widehat{\delta}$ with the $68 \%$ confidence sets (dotted lines) across overlapping windows. We assumed three lags.

While the two approaches deliver different quantitative results, especially in the final part of the sample, the qualitative picture is very similar and points to a time-varying relationship between hours and technology identifying a protracted increase in the reaction of hours to technological improvements over time. ${ }^{13}$ In all, these results confirm the existence of important changes in the short-run technology-hours correlations in the US over the post-war period.

\subsection{Why Do We Focus on the Hours-Technology CORRElation?}

Given the information set that we consider (hours, productivity and output), there is a wide array of conditional and unconditional correlations that might have experienced changes and breaks (see, for instance, Galí and van Rens (2014) and Nucci and Riggi (2013)). It is then legitimate to question why we focus exclusively on the correlation between hours and technology. There are, in fact, two good reasons for this choice.

While there is little ambiguity in the measurement of output, the construction of a measure of hours worked is less trivial. ${ }^{14}$ As mentioned earlier, and as available in the online appendix,

\footnotetext{
${ }^{13}$ We analyzed the time-varying correlation between the Fernald (2014) measure of TFP growth and the structural innovations from the SVAR. The correlations tend to fall over time. However, the correlation between the SVAR and smoothed innovations from the estimated RBC model in the next section actually increases over time.

${ }^{14}$ See Ramey (2012) for a discussion of the impact of different measures of hours on the cyclical behavior of labor productivity.
} 
we analyzed four measures of hours worked based on Galí and Gambetti (2009), Chang et al. (2007), Ríos-Rull et al. (2012), and Francis and Ramey (2009). For each of these measures, different filtering techniques and different subsamples, we looked at their second moments properties, i.e. changes in standard deviations, in unconditional correlations, and in conditional correlations. We find that very few moments display time variations that are robust across these three dimensions (i.e. data specification, filter and subsample). To support the argument, Table 1 presents some selected pre- and post-1984 statistics using all or just a portion of fluctuations, i.e. correlations and standard deviations using the specification of hours worked based on Francis and Ramey (2009). ${ }^{15}$ The decrease in the volatility of hours is visible when a large portion of medium and long run fluctuations are removed; at medium run fluctuations there are no differences between pre and post 1984. Moreover, the vanishing procyclicality of labor productivity (measured as the correlation of labor productivity with hours or output) is quite moderate and not a striking feature of the Francis and Ramey (2009) measure of hours worked. ${ }^{16}$

\begin{tabular}{lcccc} 
& All & Medium Term & Business Cycles & High Frequency \\
\hline SD hours pre/post 1984 & $2.34 / 2.85$ & $2.75 / 2.77$ & $1.51 / 1.01$ & $0.71 / 0.48$ \\
$\operatorname{corr}(p, y)$ pre/post 1984 & & $0.79 / 0.58$ & $0.68 / 0.53$ & $0.81 / 0.71$ \\
$\operatorname{corr}(p, h)$ pre/post 1984 & & $-0.12 /-0.43$ & $0.15 /-0.11$ & $0.10 /-0.05$ \\
$\operatorname{corr}(h, y)$ pre/post 1984 & & $0.51 / 0.49$ & $0.82 / 0.78$ & $0.66 / 0.67$ \\
\hline
\end{tabular}

Table 1: Volatilities and unconditional correlations pre- and post-1984 using different portion of fluctuations of hours worked.

note: High Frequency = First Difference; Business Cycles = Hodrick Prescott filter; Medium Term = Quadratic Detrending; All = raw data

Yet, there are statistics that appear to change significantly over time and whose variations appear robust across specifications. The response of hours worked to a technology shock is one of those. While there are quantitative differences, all databases and transformations (save for first differencing) display similar patterns. A second relevant robust result is the response of labor productivity to a so-called "non-technology" shock. In particular, the impact response of productivity turns from positive to negative in the final part of the sample.

The changing response of productivity to "non-technology" shocks is in itself an interesting and challenging finding. However, interpreting this evidence through the lens of a structural (DSGE) model is problematic. This is because there is no direct link between the non-technology shock of the SVAR and an equivalent shock in the DSGE model. The technology shock does have a unique mapping, i.e. it is the only shock that has full power spectra at the zero frequency both in the SVAR and in the DSGE model. While one might question if the latter is a 'technology' shock, it

\footnotetext{
${ }^{15}$ Similar statistics for the other datasets and different windows sizes can be consulted in the online appendix.

${ }^{16}$ Galí and van Rens (2014) with a bandpass filter find a change in the correlation between output and labor productivity from 0.65 to 0.25 .
} 
is unquestionable that it has the same stochastic properties in the two dynamic systems. However, the non-technology shock in the SVAR captures a transitory shock, which can be represented in the structural model in different ways such as a preference process, a government spending shock, or a temporary displacement of technology. Even if we assumed that there are only preference shocks, the way they are built in as either shocks to the discount rate or shocks to the MRS between consumption and leisure, would have consequences for their sign and size effects. A change in the response to the non-technology shock in the SVAR, thus, may simply be the consequence of changes in the proportion of the variance explained by these two different shocks, as the non-technology shock would be a composite. Absent any further restrictions, the non-technology shock of the SVAR might capture, in the best case, any of these structural shocks (or their combination) and, in the worse case, misspecification. Hence, and in line with the criticisms found in Chari et al. (2008), it would not be appropriate to draw conclusions from identifying, say, the RBC-based preference shock with the SVAR-based non-technology shock.

\section{The Structural Dynamics of Hours and Technology}

We consider a closed economy Real Business Cycles (RBC) model. The novelty of the model is that it features a Constant Elasticity of Substitution (CES) production function, which is characterized by two sources of fluctuations, a labor- and a capital-augmenting stochastic shift to the production frontier. ${ }^{17}$ The model is otherwise standard, it is a single good optimizing agent framework. On similar grounds, Francis and Ramey (2005) analyze deviations from Cobb-Douglas to explain the response of hours to technology shocks. However they examined the limiting Leontief case of a zero substitution elasticity. While this offers a potential explanation for the negative response to hours, their setup is unable to generate positive and negative responses. The advantage of our setup is that, with an elasticity of capital-labor substitution that differs from unity (the Cobb-Douglas case), even in the canonical RBC model the response of hours to a labor-augmenting technology shock can be positive or negative. Cantore et al. (2014) show analytically that the sign of the response depends crucially on the relative magnitudes of the elasticity of substitution and the capital share. The intuition behind this is that, when the elasticity of capital-labor substitution is low, for instance, a labor-augmenting technology shock increases the "effective" number of workers. But since labor is strongly complementary to capital, firms need less workers until they have enough capital to work with. This then leads to a fall in wages and a reduction in hours worked in the short run. The capital share is important as it governs the initial increase in capital stock after the technology

\footnotetext{
${ }^{17}$ The importance of the CES production function has received renewed interest during the last decade and has been shown to be important for the study of the business cycle dynamics in various contexts (see Choi and Ríos-Rull (2009), Cantore et al. (2014), Klump et al. (2012), Cantore, Levine, Pearlman and Yang (2015), León-Ledesma and Satchi (2016) and Di Pace and Villa (2016)).
} 
shock. Hence, ex ante, the model is able to generate conditional correlations between hours and technology of either sign.

We then bridge the model to observed data on US productivity and hours worked. We estimate the parameters of the RBC-CES model on rolling windows of the same fixed length as the SVAR and we look closely at propagation mechanism of the structural shocks. Let the solution of the DSGE model be of the form,

$$
\begin{aligned}
y_{t+1}^{\dagger} & =\Phi(\vartheta) y_{t}^{\dagger}+\Psi(\vartheta) \eta_{t+1} \\
x_{t} & =S y_{t}^{\dagger}
\end{aligned}
$$

where the vector $y_{t}^{\dagger}$ contains the endogenous variables of the model, $S$ is a selection matrix that picks hours and productivity growth from the vector of endogenous variables, and $\eta_{t}$ is the structural vector of innovations with zero mean and diagonal covariance matrix $\Sigma_{\eta}$. $\Phi$ and $\Psi$ are matrices which are non-linear functions of the structural parameters of the model, $\vartheta$. Since we have a unique mapping from the structural parameters of the model to the reduced form matrix, we can back out the 'deep' parameters responsible for the changes (if any) in the transmission of shocks. Then, we look closely at the time pattern of the estimated structural parameters and try to provide intuition for such changes. $^{18}$

\subsection{The RBC model and the Elasticity of Substitution}

The representative household is characterized by separable preferences in consumption and leisure.

$$
U_{t}=\ln C_{t}-V_{t} \frac{H_{t}^{1+\gamma}}{1+\gamma},
$$

where $C_{t}$ denotes consumption, $H_{t}$ hours worked, $\beta$ is the discount factor, $\gamma$ is the inverse of the Frisch elasticity, $V_{t}$ is a preference shock process that has an $\mathrm{AR}(1)$ representation, i.e. (in log deviations from the steady state) $v_{t}=\rho_{v} v_{t-1}+\eta_{t}^{v} \quad \eta_{t}^{v} \sim N\left(0, \sigma_{v}\right)$. The production function is CES and presented in normalized form as in Cantore et al. $(2014)^{19}$

$$
Y_{t}=y\left[\alpha\left(\frac{Z_{t}^{k} K_{t-1}}{k}\right)^{\frac{\sigma-1}{\sigma}}+(1-\alpha)\left(\frac{Z_{t}^{h} H_{t}}{h}\right)^{\frac{\sigma-1}{\sigma}}\right]^{\frac{\sigma}{\sigma-1}}
$$

where, as usual, output is produced by a combination of two factors, $K_{t-1}$ the installed physical capital at time $t$, and $H_{t} . y$ and $k$ are the steady state values of output and capital re-scaled by

\footnotetext{
${ }^{18}$ We also perform a 'reverse' exercise in the same spirit of Erceg et al. (2005). We ask whether the estimates of the SVAR on data simulated from our structural model would yield similar results to those obtained with the SVAR on actual data. Results are available in the the online Appendix.

${ }^{19}$ Normalization is required to compare responses when we change the elasticity of substitution. Also, it allows us to interpret directly the share parameter $\alpha$ as the capital income share at the point of normalization (the steady state in this case). Normalization, hence, allows to change $\sigma$ in calibration without having to recalibrate the rest of the parameters of the model. See Cantore et al. (2014) for normalization in the context of DSGE models.
} 
the labor augmenting process, and $h$ is the steady state value for hours. $\alpha$ and $\sigma$ are parameters controlling the capital share in production and the degree of substitutability between factors. As $\sigma \rightarrow 0$, factors are net complements, and the production function is Leontieff. If $\sigma \rightarrow \infty$ factors are net substitutes and the production function is linear. As $\sigma$ approaches 1, we have a Cobb-Douglas production function. The CES production function encompasses two types technological change, i.e. the capital augmenting, $Z_{t}^{k}$, and the labor augmenting technological process, $Z_{t}^{h}$. We assume that capital-augmenting technology has an $\mathrm{AR}(1)$ representation, i.e. (in log deviations from the steady state) $z_{t}^{k}=\rho_{k} z_{t-1}^{k}+\eta_{t}^{k} \quad \eta_{t}^{k} \sim N\left(0, \sigma_{k}\right)$, where $\rho_{k}<1$ to ensure the existence of a balanced growth path in accordance with Uzawa (1961). For the labor-augmenting shock we adopt an autoregressive process in growth rates, i.e. $z_{t}^{h}-z_{t-1}^{h}=\rho_{h}\left(z_{t-1}^{h}-z_{t-2}^{h}\right)+\eta_{t}^{h}$, with $z_{t}^{h}=\ln Z_{t}^{H}-\ln Z_{0}^{H}$. With a technology process persistent enough in growth rates, Lindé (2009) showed that the response of hours can be negative even in a standard RBC model. Parameter $\rho_{h}$ can, ex ante, also generate time variations in the response of hours in our setting. Hence, changes in the diffusion of the technology shock offer an alternative explanation for changes in the response of hours even in this simple setting. By estimating the two parameters jointly, we are able to quantify the importance of these two structural parameters for the observed changes. The model is then closed by assuming that capital depreciates at rate $\delta$ and that the economy's resource constraint is given by: ${ }^{20}$

$$
Y_{t}=C_{t}+K_{t}-(1-\delta) K_{t-1}
$$

As mentioned, this model has the property that the capital intensity in production and the elasticity of factor substitution, $\alpha$ and $\sigma$, are the main drivers of the dynamics of output and hours worked conditional on a labor augmenting technology shock.

By means of a sensible calibration exercise, we can study the impact of a labor augmenting technology shock on hours worked for different values of the capital-labor substitution elasticity. We let the capital-labor elasticity vary between 0.1 and 1 , and we fix the capital share in production to 0.33 . Figure 4 (left panel) reports the impulse response of hours worked to a labor-augmenting technology shock for different values of $\sigma$ and keeping the value of $\alpha$ fixed at 0.33. Approximately, when $\sigma>\alpha$ the response of hours to a labor augmenting technology shock is positive. However, hours worked decrease if $\sigma<\alpha$. The right panel of Figure 4 displays the instantaneous response of hours worked to a labor-augmenting technology shock for different values of $\sigma$ and $\alpha$. We let the value of $\alpha$ vary between 0.2 to 0.6 . For values in the neighborhood $\sigma=0.7$ and above the response of hours switches to positive regardless of values of $\alpha$. The intuition behind the result is that the shock induces a substitution effect that reduces the demand for labor $\left(\frac{1-\sigma}{\sigma}\right)$ as capital is fixed in the short-run, and a quantity effect that increases the demand for labor because of the increase in output $\left(\frac{1-\alpha}{\sigma}\right)$. Depending on the strength of these two, hours may increase or decrease.

\footnotetext{
${ }^{20}$ The full model is described in section 5 of the online appendix.
} 

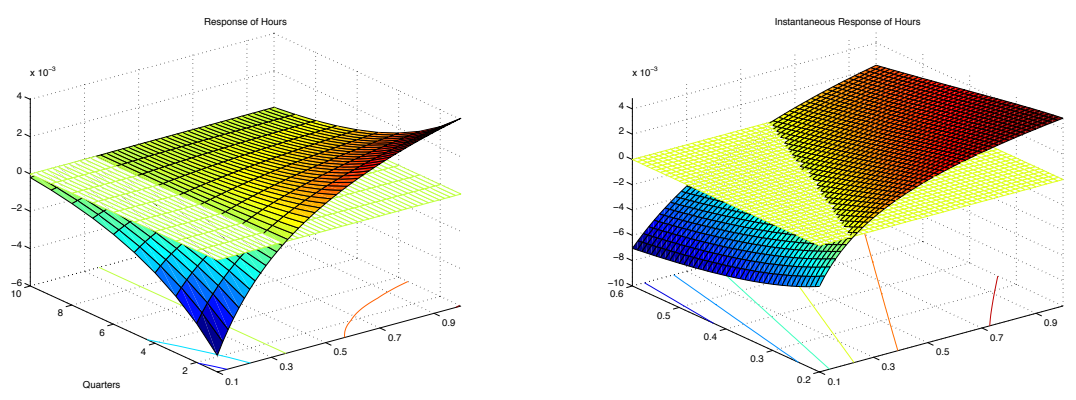

Figure 4: Impulse response of hours worked to a labor-augmenting technology shock for different values of $\sigma$ and $\alpha=0.33$ (Left panel). Instantaneous response of hours worked to a labor-augmenting technology shock for different values of $\sigma$ and $\alpha$ (Right Panel).

\subsection{THE DYNAMIC TRANSMISSION OF TECHNOLOGY SHOCKS}

We estimate the structural parameters of model by combining prior information and the likelihood of the data in each of the rolling windows. We estimate the model using the same data on observables as in the VAR analysis. The choice of priors is standard. We assume an inverse gamma for standard deviations, beta distributions for the autoregressive parameters centered in 0.5 , a normal distribution for the inverse of the Frisch elasticity, $\gamma$, and for the capital intensity in production, $\alpha$. The prior for $\sigma$ follows a gamma distribution centered around 0.5 and with a loose precision. ${ }^{21}$ For conciseness, we do not report the posterior estimates as they can be consulted in the online appendix. The results, however, showed that that data are very informative regarding the parameters of interest. The key fact that our setup aims to explain is the time varying relationship between hours and technology shocks and, in particular, if the model is able to reproduce the patterns found using the SVAR model. Figure 5 plots the response of hours worked to a labor augmenting technology shock. The response of hours worked shows clear shape and sign variations along the sample. Taken literally, the very early samples are characterized by a negative response. Then, the reaction of hours steadily increases and settles around positive values in the last ten rolling windows. The resemblance

\footnotetext{
${ }^{21}$ Given the difficulty reported in the literature to identify parameter $\sigma$ (see León-Ledesma et al. (2010)), we carried out number of experiments to check its identifiability with simulated data. We find that, with 100 data points, labor productivity and hours worked contain enough information to pin down the parameters of interest with a flat prior on $\sigma$ and standard priors on the remaining parameters. Results can be consulted in the online appendix.
} 


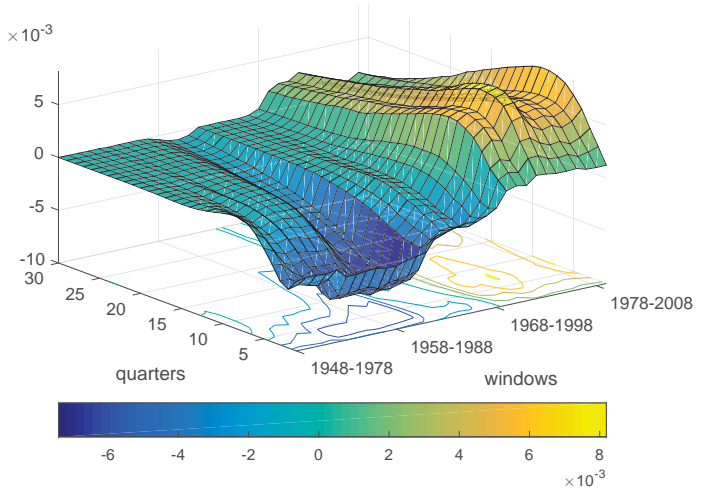

(a) SVAR

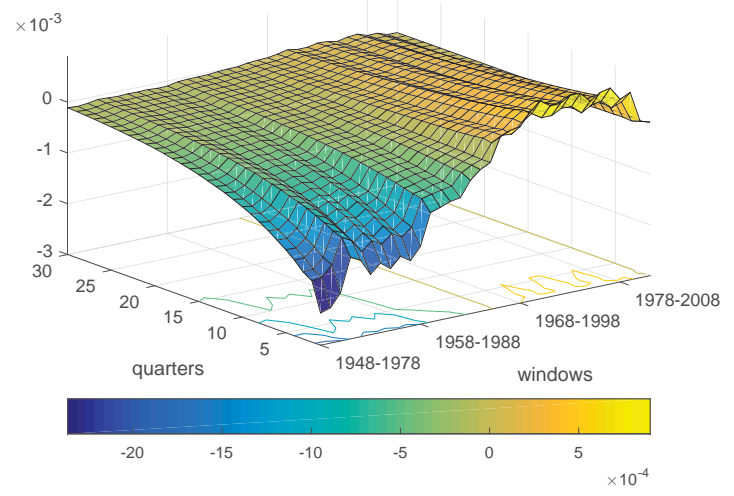

(b) RCB-CES

Figure 5: Median impulse responses of hours to a positive labor augmenting technology shock.

with the SVAR evidence is remarkable. On impact, the signs of the response of hours are correctly identified. Figure 6 plots the $90 \%$ credible sets around the instantaneous response of hours with the
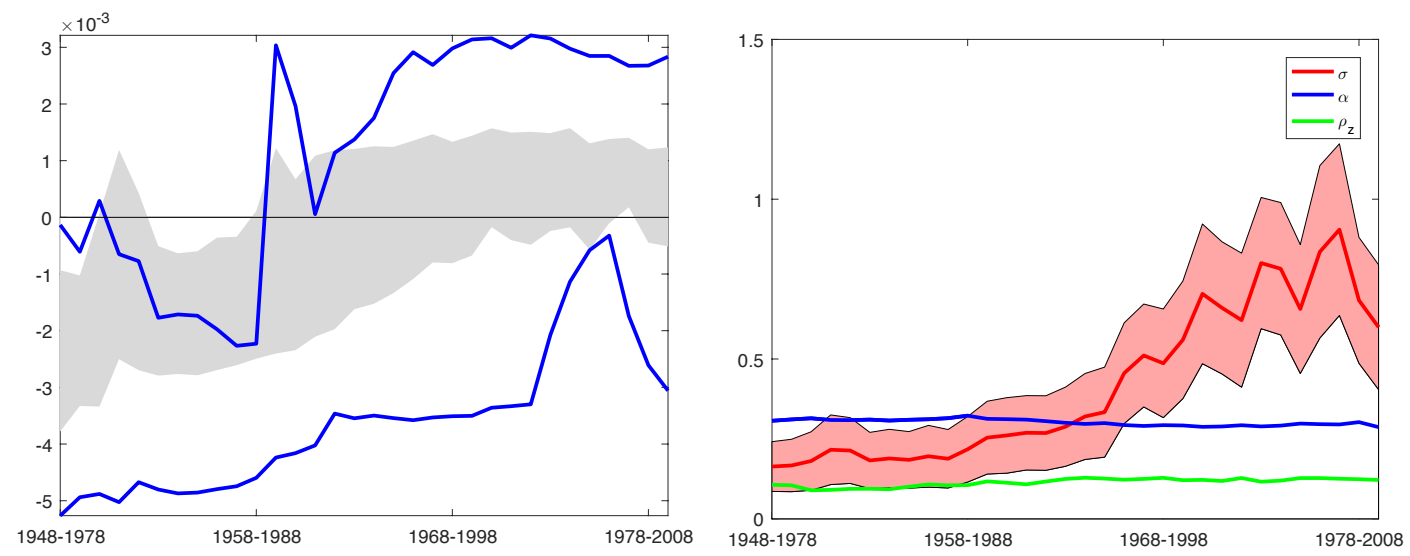

Figure 6: On the left panel credible sets of the contemporaneous impact of hours to a technology shock in the SVAR (blue line) and in the RBC with CES (grey shaded area). On the right panel, the median estimates of $\alpha$ (blue), $\rho_{h}$ (dashed), $\sigma$ (red) and its credible sets (red shaded area).

SVAR estimates and the RBC-CES. If the instantaneous response of hours were different in the two settings, we would observe windows with non overlapping bands. It is important to note that the bands around the RBC-CES are tighter than the SVAR, and this is partly due to the proper priors imposed on the structural parameters as opposed to the flat priors on the reduced from coefficients of the SVAR. The difference in the amount of uncertainty around the impact is also due to the structure of the DSGE model whose solution is typically embedded with tight restrictions on the autoregressive part of the dynamic model. With these caveats in mind, we find that the difference 
between the contemporaneous response of hours in the estimates of the SVAR and the estimates of the RBC-CES model do not appear to be significant. ${ }^{22}$

The question that follows is: what are the driving parameters behind the change in the propagation mechanism? Since the impulse response is computed as the marginal impact of a structural innovation to a variable, we can rule out changes in the standard deviations of the structural shocks as responsible for such variations. Even if the model is very stylized, the CES production function allows us to disentangle the scenarios where hours increase (decrease) in response to a technology innovation because the degree of factor substitution is larger (smaller) than the capital share in production. While we find little variations in the estimates of the persistence of the growth process for technology, there are large variations in the posterior estimates of the elasticity of factor substitution, in absolute terms and relative to the capital share parameter in production, $\alpha$. Figure 6 (right panel) plots the posterior mean of the elasticity of substitution, the capital share and the autoregressive parameter in each of the sub-samples. Changes in the hours-technology conditional correlation on impact are associated with changes in the elasticity of capital-labor substitution. ${ }^{23}$

There is an expanding literature on time variation in DSGE model parameters. FernandezVillaverde and Rubio-Ramirez (2008) and Justiniano and Primiceri (2008) model time variation by assuming stochastic processes for a subset of the parameters and include these in the set of state equations. Fernandez-Villaverde and Rubio-Ramirez (2008) assume that agents in the model take into account current and future parameter variation utilizing the parameters' representation as stochastic processes when computing their expectations. In contrast, Canova (2006) and Giacomini and Rossi (2016) assess parameter time variation by estimating DSGE models over rolling samples. A similar strategy was followed by Castelnuovo (2012) and Canova and Ferroni (2012). Galvao, Giraitis, Kapetanios and Petrova (2015) have recently proposed a local Bayesian estimator methods to capture local instabilities. It is useful to contrast both of these strands. The first strand makes parametric assumptions about the nature of time variation. These assumptions are not microfounded and have a reduced form flavor. Instead, our method is agnostic about the source of the variation apart from assuming that it is slow. Given that such changes are likely to be the result of long term structural shifts that no mainstream business cycle model is well equipped to explain, this agnostic approach has merit. A further issue is that computational complexity restricts the ability of allowing for time variation to only a small subset of the model parameters whereas a rolling sample estimation is scaleable to the full set of parameters. In section 4.1 we also discuss alternative estimates of the time variation of $\sigma$ which point in the same direction as the evidence presented thus far. ${ }^{24}$

\footnotetext{
${ }^{22}$ However, given the wide credible sets, especially for the SVAR, we need to consider further this comparison as we do in section 6 of the online Appendix.

${ }^{23}$ The figure also reports the credible sets of the estimation of the elasticity of substitution showing how the estimated increase in this parameter is statistically significant.

${ }^{24}$ It is also worth noting that, with $\sigma<1$, the model generates a counter-cyclical labor share. The increase in $\sigma$
} 


\section{Robustness And alternative Explanations}

\subsection{The DYNAMics of AgGREGATE PRODUCTION}

Given the large and, arguably, radical increase in $\sigma$ in the structural estimate of the RBC-CES model, we analyze whether the resulting estimates of this parameter arising from an alternative estimation method are in line with these findings. We applied the normalized system estimation method proposed by León-Ledesma et al. (2010) that consists of the joint nonlinear estimation of the CES production function and the first order conditions for labor and capital. The method allows for the joint identification of $\sigma$ and biased technical change parameters. We applied this method to rolling windows for US data. Given the data requirements in this approach, which include data on the user cost of capital, wages, factor inputs and output, we used an annual database (1952-2009) discussed in León-Ledesma et al. (2015). ${ }^{25}$ We estimated the system on rolling windows of 40 years starting in 1952 and rolling the window a year at a time. Smaller windows led to less reliable parameter estimates. We thus obtained 19 estimates of $\sigma$ which are plotted in Figure 7 for each starting year of the rolling window together with $90 \%$ confidence intervals. The estimates clearly show a protracted increase in $\sigma$ throughout the sample with a timing comparable to that obtained in the structural estimates of the RBC-CES model. ${ }^{26}$ The increase observed in these estimates is less pronounced than in our previous results, although the increase is still very substantial. Thus, compatible with the evidence presented in section 3.2, these alternative estimates of the elasticity of capital-labor substitution also point towards substantial increases in $\sigma$ as a potential source of changes in the transmission of productivity shocks.

\subsection{Competing Structural interpretations}

As mentioned in the introduction, there are a number of structural interpretations that could be advocated to explain the SVAR evidence. Since there are several potential explanations for the observed reaction of hours to technology shocks in the literature, one could argue that changes in some key parameters for these explanations have driven the changes in the response of hours. As argued earlier, explanations based on changes in labor market rigidities (and also price rigidities) cannot account for the sign switch observed in the data. Other explanations can relate to the change in monetary policy regime in the US in the 1980s (Galí et al. (2003)). Also, supply side factors

should thus be associated with a decrease in that counter-cyclicality. Using US quarterly data for the 1948:1-2013:2 period, the correlation of the labor share with output growth was -0.31. For the 1948-1981 sub-sample it was -0.51, whereas for the 1982-2013 sub-sample it fell to -0.03.

${ }^{25}$ For details about the data and estimation methods we refer to the above mentioned sources since our intention here is simply to analyze the robustness of our finding relating to the increase in $\sigma$ throughout the sample period.

${ }^{26}$ The estimates using the normalized system approach are larger than those arising from the direct estimate of the $\mathrm{RBC}$ model. This is to be expected as the RBC estimates emphasise higher frequencies in the data which, generally, tend to yield lower estimates of $\sigma$ as shown in Chirinko and Mallick (forthcoming). Nevertheless, the relevant elasticity at business cycle frequencies remains the one arising from the estimate of the RBC model. 


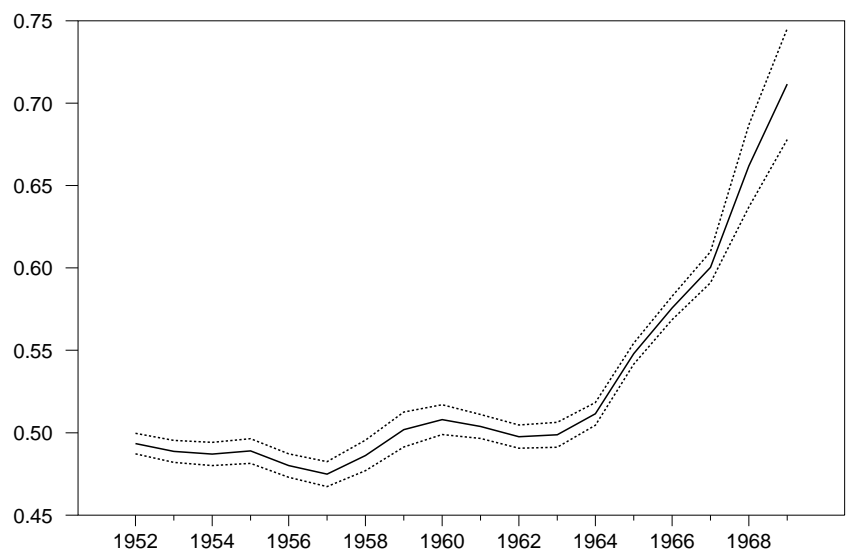

Figure 7: Elasticity of substitution estimation. Normalized system estimation method. Dotted lines are $90 \%$ confidence intervals.

such as changes in the persistence of technology shocks, habits in consumption, and investment adjustment costs could have contributed to changes in the technology-hours correlation. Along the lines of models with real frictions, Rebei (2014) finds that a model with both consumption habits and investment adjustment costs does a good job at explaining the negative response of hours after a technology shock for the US. We thus carried out the following robustness checks on these competing interpretations: ${ }^{27}$

1. Monetary policy. We simulated the Galí et al. (2003) model with a money rule and an interest rate rule regime and estimated our RBC-CES model using this simulated data. Our results reveal that monetary policy changes could not have driven the change in the parameter values that we observe in our model. The change in monetary regime also generates several counterfactual results.

2. Persistence of technology shocks. Lindé (2009) argues that the persistence of rate of growth shocks to technology can change the response of hours to technology shocks. However, our estimates (see figure 6) show that changes in $\rho_{h}$ cannot be driving the change in the response of hours. $\rho_{h}$ varies very little across sub-samples and, if anything, it goes in the opposite direction.

3. Investment adjustment costs. With large (small) enough investment adjustment costs it is possible to generate positive (negative) responses of hours to a technology shock on impact in a standard RBC model (Albonico, Kalyvitis and Pappa (2012)). We carried out an a-priori calibration sensitivity analysis and estimated this version of the model with Cobb-Douglas

\footnotetext{
${ }^{27}$ Full explanations and results are provided in the online appendix sections 8,9 , and 10 to which we refer the reader for details.
} 
production for the same rolling sub-samples as for our RBC-CES model but we did not find any sign switch in the response of hours. ${ }^{28}$

4. Habit persistence with investment adjustment costs. In a standard RBC model with both internal consumption habits and investment adjustment costs, it is possible to obtain a sign switch in the response of hours albeit for implausible parameter values. We estimated such model for the same rolling sub-samples as for our RBC-CES model and find that it is unable to match the change in the response of hours observed in the data.

\section{RAtionAlizing CHANGES IN THE ELASTICITY OF SUBSTItUTiON}

Our analysis suggests that the driving factor behind the change in the response of hours is the increase in the elasticity of capital-labor substitution $\sigma$. This means that the parameter is not structural in a strict sense. Changes in deep parameters such as, e.g., the degree of risk aversion, are commonly used the explain the existence of instabilities in macroeconomic relationships. However, the observed change in $\sigma$ deserves further attention. We propose here an explanation based on a production function with heterogeneous inputs where either changes in the composition of inputs or their relative efficiency can lead to changes in the aggregate elasticity of capital-labor substitution. Note that our focus remains on the response of aggregate hours to technology shocks. In this sense, we focus on potential explanations for changes in the elasticity of substitution between capital and aggregate hours as in the RBC-CES model.

Several authors such as Hicks (1932) and La Grandville (1989) have proposed that the elasticity of substitution can react endogenously to changes in the macroeconomy. This is formalized in Miyagiwa and Papageorgiou (2007), who present a multisector growth model where $\sigma$ is endogenously determined by economic development. Similarly, Álvarez Cuadrado, Long and Poschke (Forthcoming) analyze a multisector model of structural change where the aggregate elasticity of substitution is endogenous as capital intensity increases in the more flexible sectors (i.e. those with higher elasticity of substitution).

A key source of heterogeneity in production inputs is differences in skills within the labor force. I.e., a production function that uses capital and different kinds of labor (skilled and unskilled). In a standard two-inputs CES production function, $\sigma$ is constant. However, in the presence of heterogeneous inputs, the aggregate elasticity of substitution between capital and aggregate labor is not constant and will depend, among other things, on the share of these heterogeneous inputs. We focus here on the case of a CES function with capital, skilled and unskilled workers as production inputs and use the common specification of a two-level nested CES function. The effects that changes

\footnotetext{
${ }^{28}$ Results are very similar to the ones for the model with both investment adjustment costs and consumption habits and are available upon request.
} 
in the shares of skilled and unskilled workers have on $\sigma$ will depend on the (constant) elasticities of substitution between the three inputs, and the type of nesting specified for the CES. ${ }^{29}$ In what follows, we analyze the effect of changes in the shares of these inputs. ${ }^{30}$ The increased importance of skilled workers and skill-biased technical change has been a central feature of the structural change experienced by the US labor market in the past four decades (see Acemoglu and Autor (2011)).

It is worth noting that, in the derivations below, we assume these shares to be exogenous, and we only analyze the effect of these changes on the aggregate elasticity of substitution. That is, we are implicitly assuming that the relative importance of skilled workers is determined outside the model. A full model where these shares are determined endogenously would require a model of induced bias in technical change capable of explaining the increasing importance of skilled workers in production. We leave this for future research and here we assume that the shares of skilled workers or their relative efficiency are determined exogenously. ${ }^{31}$

Without loss of generality, and for simplicity, we ignore technological process terms and time subscripts and assume all variables are measured at the normalization point. We denote skilled labor as $S$ and unskilled labor as $U$. The first nesting corresponds to:

$$
\begin{aligned}
& Y=\left[\pi_{X} X^{\psi}+\left(1-\pi_{X}\right) U^{\psi}\right]^{1 / \psi} \\
& X=\left[\pi_{K} K^{\theta}+\left(1-\pi_{K}\right) S^{\theta}\right]^{1 / \theta},
\end{aligned}
$$

where $\psi$ and $\theta$ are the inter- and intra-class substitution parameters, $\pi_{X}$ is the income share parameter for aggregator $X$ at the point of normalization, and $\pi_{K}$ is the share parameter of capital in $X$ (also at the normalization point). The corresponding elasticities of substitution are $\sigma_{K, S}=\frac{1}{1-\theta}$ and $\sigma_{K, U}=\sigma_{S, U}=\frac{1}{1-\psi}$ with $-\infty<\theta<1$ and $-\infty<\psi<1$. Note that the Cobb-Douglas case occurs when $\psi(\theta)=0$, the Leontief case when $\psi(\theta)=-\infty$, and the perfect substitutes case when $\psi(\theta)$ $=1$. The second nesting is:

$$
\begin{aligned}
& Y=\left[\pi_{X} X^{\psi}+\left(1-\pi_{X}\right) S^{\psi}\right]^{1 / \psi} \\
& X=\left[\pi_{K} K^{\theta}+\left(1-\pi_{K}\right) U^{\theta}\right]^{1 / \theta},
\end{aligned}
$$

where parameters have the same interpretation as in (5)-(6), but now $\sigma_{K, U}=\frac{1}{1-\theta}$ and $\sigma_{K, S}=$

\footnotetext{
${ }^{29}$ See Papageorgiou and Saam (2008) for a theoretical examination of the properties of similar production technologies.

${ }^{30}$ Note that, as will be apparent below, this is equivalent to analyzing the effects of changes in skilled-saving relative to unskilled-saving technical change (which is skill-biased technical change if both are gross substitutes in production). Under equal elasticities of substitution, it would also be equivalent to a change in the proportion of workers towards skill-intensive sectors.

${ }^{31}$ Business cycle models with skilled and unskilled workers that assume CES aggregators and biased technology shocks such as investment-specific shocks face the challenge that these shocks have to be temporary for a balanced growth path to be attainable. Permanent shocks lead to ever changing cost shares. This is not the case, of course, with Cobb-Douglas technologies. However, with Cobb-Douglas, technology shocks are neutral for factor shares. Given that it is hardly defensible that biased technology innovations are temporary, this constitutes an important modeling challenge.
} 
$\sigma_{S, U}=\frac{1}{1-\psi}$. And the third nesting is:

$$
\begin{gathered}
Y=\left[\pi_{X} X^{\psi}+\left(1-\pi_{X}\right) K^{\psi}\right]^{1 / \psi} \\
X=\left[\pi_{S} S^{\theta}+\left(1-\pi_{S}\right) U^{\theta}\right]^{1 / \theta},
\end{gathered}
$$

where we have $\sigma_{S, U}=\frac{1}{1-\theta}$ and $\sigma_{K, S}=\sigma_{K, U}=\frac{1}{1-\psi}$.

The nestings differ in terms of the assumptions imposed about the value of the elasticity of substitution across factors. While in the first nesting both $K$ and $S$ are equally substitutable for $U$ but not between them, in nesting two both $K$ and $U$ are equally substitutable with $S$ but not between them. Nesting (5)-(6) has been widely used in the capital-skill complementarity literature as discussed in Krusell, Ohanian, Ríos-Rull and Violante (2000). Capital-skill complementarity in this nesting simply implies that $\psi>\theta$. In nesting two, however, capital-skill complementarity implies that $\theta>\psi$ such that capital is more substitutable with $U$ than with $S$. Note, however, that the third nesting does not allow for capital-skill complementarity as both skilled and unskilled workers are assumed to substitute capital the same way. In fact, it is easy to show analytically that, in this case, the aggregate elasticity of substitution between labor and capital is simply $\frac{1}{1-\psi}$ which is constant. Hence, we leave aside the third nesting as, by construction, it cannot generate time-variation of $\sigma$.

In order to analyze the effect of changes in the proportion of skilled workers in the first two nestings, we define $n=\frac{U}{U+S}$ as the fraction of unskilled workers. Since total labor input is $H=U+S$, we can write $U=n H$ and $S=(1-n) H$. Now, we use the definition of the aggregate elasticity of substitution $\sigma$ :

$$
\sigma=\frac{\frac{w / r}{K / H}}{\frac{\partial(w / r)}{\partial(K / H)}},
$$

where $r$ is the rental price of capital. Note also that, at the normalization point, $\frac{w}{r}=\frac{1-\pi_{X} \pi_{K}}{\pi_{X} \pi_{K}} \frac{K}{H}$. Using this and expression (11), Papageorgiou and Saam (2008) show that the aggregate elasticity of substitution between $H$ and $K$ is a harmonic mean of the elastcities of substitution in the nested CES functions that can be expressed as:

$$
\begin{gathered}
\sigma=\frac{1}{(1-\theta)+(\theta-\psi) g}, \\
g=\frac{\pi_{K}}{\frac{1-\pi_{K}}{1-\pi_{X}}+\pi_{K}} .
\end{gathered}
$$

Since $\theta$ and $\psi$ are constants, we can analyze the effect of a change in $(1-n)$ on $\sigma$ by obtaining the derivative of $g$ with respect to $(1-n)$. We are then in a position to state the following lemma:

Lemma 1 The aggregate capital-labor elasticity of substitution $\sigma$ is a positive function of the share of skilled workers $(1-n)$ (and the productivity of skilled relative to unskilled workers) if:

1. $|\theta|>|\psi|$ for the first three-factor CES nesting $(X, U)$; 
2. $|\theta|<|\psi|$ for the second three-factor CES nesting $(X, S)$.

Proof. See Appendix A.

Take the first nesting. This condition would imply that if capital and skills are complements (within the $X$ aggregator), i.e. $\theta<0$, and unskilled workers and $K$ and $U$ substitutes $(\psi>0)$, the degree of complementarity between $K$ and $S$ has to be stronger than the degree of substitutability between $U$ and the other two factors. On the other hand, this would also be the case if all factors are substitutes $(\theta>0$ and $\psi>0)$ but $U$ is less substitutable for $X$ than $S$ and $K$ are between each other. The same conclusions apply for the other nesting bearing in mind that, in this case, $\theta>\psi$ implies capital-skill complementarity.

The question is, of course, how likely is this to be the case? Estimates of the skilled-unskilled workers substitution parameter $\psi$ usually range between 0.25 and $0.5 .{ }^{32}$ Regarding substitution between capital and skilled workers, estimates differ by study and are less abundant. Krusell et al. (2000) find and elasticity of $0.67(\theta \simeq-0.5)$. However, given that aggregate $\sigma$ is estimated to be substantially below unity (see Chirinko (2008)) and our estimates for the full sample are below 1 , this elasticity is likely to be even lower. Hence, the conditions for a positive effect of $1-n$ on $\sigma$ are plausible.

Based on this, we carry out a simple numerical exercise. We calibrate $\psi$ to a value of 0.33 (corresponding to an elasticity of 1.5). Baseline values for the shares are $\pi_{X}=0.6$ and $\pi_{K}=0.5$, corresponding to a an aggregate capital income share of 0.27 and a skilled income share of 0.33 . The initial share of skilled workers as a proportion of total workers is $20 \%(n=0.2)$. To be compatible with our low $\sigma$ estimate, we then $\operatorname{set} \theta=-3$ corresponding to a plausible elasticity of 0.25 . The value of the aggregate elasticity of substitution yields 0.32 . We then analyze the impact of an increase of the share of skilled workers of 0.25 (25 percentage points) similar to that observed in the data. ${ }^{33}$ The corresponding new value for $\sigma$ is almost 0.9. This large change is thus compatible with that observed in our estimates. ${ }^{34}$

\footnotetext{
${ }^{32}$ For evidence on the elasticity of substitution between workers by skill level see, amongst many others, Katz and Murphy (1992), Autor, Katz and Krueger (1998), Ciccone and Peri (2005) and Autor, Katz and Kearney (2008). Most of these estimates range between 1.3 and 2.5, with consensus estimates around 1.5, corresponding to $\psi=0.33$.

${ }^{33}$ Autor et al. (2008) report an increase in the share of college-plus hours as a share of high school-plus hours in the US from around $20 \%$ in 1963 to about $45 \%$ in 2005 . We use these values to approximate the increase in the share of skilled workers in this exercise.

${ }^{34}$ Recently, Balleer and van Rens (2013) analyze the effect of skill-biased technology shocks on the labor market using a SVAR identification scheme. Their findings show that the response of the wage premium to investment-specific shocks is incompatible with capital-skill complementarity. Their preferred model would display a strong capital-skill substitutability such that $\theta>\psi>0$. This would also be compatible with the results from Lemma 1. Nevertheless, we note that this would imply an aggregate $\sigma$ much larger than 1, which clashes with a large body of evidence for the US where $\sigma \ll 1$.
} 


\section{Conclusions}

We present further evidence and robustness on the time-varying conditional correlation between hours and technology innovations in the post-war US economy and offer a structural explanation for such variation. We argue that the change in the response of hours to technology shocks relates to changes in key supply side parameters of the economy. Specifically, the change in the elasticity of capital-labor substitution.

We first report evidence based on a SVAR model with long-run restrictions and a reduced form model using an empirical measure of TFP on rolling sub-samples. Consistent with previous results, we report that the conditional correlation between hours and the technology shock has increased over time becoming positive in the later parts of the sample. This pattern is also robust to data definitions and filtering methods. We then offer a structural interpretation of this change using a parsimonious RBC model with a Constant Elasticity of Substitution production function. Within this setting, the sign of the response of hours crucially depends on the magnitude of the elasticity of capital-labor substitution.

The model is estimated using Bayesian methods for overlapping samples of the same length as the SVAR. We find that there is a significant sign variation of the response of hours worked to a positive technology shock and that this time-varying impulse response tracks satisfactorily the changes observed in the data-based SVAR despite its parsimonious nature. Such variation is driven by a change in the magnitude of the elasticity of factor substitution: we observe an increase in the elasticity of capital-labor substitution towards the end of the sample that leads to a change in the sign and size of the response of hours. The elasticity, however, remains below one (the Cobb-Douglas case) for all the sub-samples. We show that the impact response of hours obtained from applying a SVAR on data simulated from the estimated RBC-CES model is close to that obtained with actual data.

We argue that that the observed increase in the aggregate elasticity of capital-labor substitution may be the result of structural changes in the supply side of the economy. These are associated with shifts in the skill composition of the labor force (and biased technical change). Finally, we show that our explanation for the change in the response of hours to technology shocks competes favourably against alternative explanations. Although we do not claim that changes in frictions and macroeconomic policies do not play a role in contributing towards the dynamics of hours and technology, we emphasize the importance of deeper changes in the structure of the US economy as a key driver of this important time-varying macroeconomic correlation. This also opens avenues for future research such as a business cycle model with heterogeneous labor where biased technology shocks drive different responses by type of labor. This would allow us to better understand the links between the changing dynamics of the response of hours to technology shocks, the skill composition 
of the labor force, and the different sources of technological shocks (i.e. neutral vs. biased).

\section{REFERENCES}

Acemoglu, D. and Autor, D. H.: 2011, Skills, tasks and technologies: Implications for employment and earnings, in O. Ashenfelter and D. E. Card (eds), Handbook of Labor Economics Volume 4, Amsterdam: Elsevier.

Albonico, A., Kalyvitis, S. and Pappa, E.: 2012, Revisiting the Productivity-Hours Puzzle in the RBC Paradigm: The Role of Investment Adjustment Costs, Quaderni di Dipartimento 164, University of Pavia, Department of Economics and Quantitative Methods.

Alexopoulos, M.: 2011, Read all about it! What happens following a technology shock?, American Economic Review 101(4), 1144-79.

$\Omega$ Álvarez Cuadrado et al.

Álvarez Cuadrado, F., Long, N. and Poschke, M.: Forthcoming, Capital-labor substitution, structural change and growth, Theoretical Economics .

Autor, D. H., Katz, L. F. and Kearney, M. S.: 2008, Trends in U.S. Wage Inequality: Revising the Revisionists, The Review of Economics and Statistics 90(2), 300-323.

Autor, D. H., Katz, L. F. and Krueger, A. B.: 1998, Computing inequality: Have computers changed the labor market?, The Quarterly Journal of Economics 113(4), 1169-1213.

Balleer, A. and van Rens, T.: 2013, Cyclical Skill-Biased Technological Change, Review of Economics and Statistics, 95(4), 1222-1237.

Basu, S., Fernald, J. G. and Kimball, M.: 2006, Are technology improvements contractionary?, American Economic Review 96, 1418-1448.

Canova, F.: 2006, Monetary Policy and the Evolution of the US Economy, Cepr discussion papers, C.E.P.R. Discussion Papers.

Canova, F. and Ferroni, F.: 2012, The dynamics of US inflation: Can monetary policy explain the changes?, Journal of Econometrics 167(1), 47-60.

Canova, F. and Gambetti, L.: 2009, Structural changes in the US economy: Is there a role for monetary policy?, Journal of Economic Dynamics and Control 33(2), 477-490.

Canova, F., Lopez-Salido, D. and Michelacci, C.: 2010, The effects of technology shocks on hours and output: a robustness analysis, Journal of Applied Econometrics 25(5), 755-773. 
Cantore, C., León-Ledesma, M. A., McAdam, P. and Willman, A.: 2014, Shocking stuff: technology, hours, and factor substitution, Journal of the European Economic Association 12(1), 108-128.

Cantore, C., Levine, P., Pearlman, J. and Yang, B.: 2015, CES technology and business cycle fluctuations, Journal of Economic Dynamics and Control 61(C), 133-151.

Castelnuovo, E.: 2012, Estimating the Evolution of Money's Role in the U.S. Monetary Business Cycle, Journal of Money, Credit and Banking 44(1), 23-52.

Chang, Y., Doh, T. and Schorfheide, F.: 2007, Non-stationary Hours in a DSGE Model, Journal of Money, Credit, and Banking 69(6), 1357-1373.

Chang, Y. and Hong, J. H.: 2006, Do technological improvements in the manufacturing sector raise or lower employment?, American Economic Review 96(1), 352-368.

Chari, V., Kehoe, P. J. and McGrattan, E. R.: 2008, Are structural VARs with long-run restrictions useful in developing business cycle theory?, Journal of Monetary Economics 55(8), 1337-1352.

Chirinko, R. S.: 2008, $\sigma$ : The Long and Short of It, Journal of Macroeconomics 30(2), 671-686.

Chirinko, R. S. and Mallick, D.: forthcoming, The Substitution Elasticity, Factor Shares, and the Low-Frequency Panel Model, American Economic Journal: Macroeconomics .

Choi, S. and Ríos-Rull, J.-V.: 2009, Understanding the Dynamics of the Labor Share: the Role of non-Competitive Factor Prices, Annales d'Economie et de Statistique (95-96), 251-277.

Christiano, L. J., Eichenbaum, M. and Vigfusson, R.: 2003, What happens after a technology shock?, NBER Working Papers 9819, National Bureau of Economic Research, Inc.

Ciccone, A. and Peri, G.: 2005, Long-Run Substitutability Between More and Less Educated Workers: Evidence from U.S. States, 1950-1990, The Review of Economics and Statistics 87(4), 652663.

Clarida, R., Galí, J. and Gertler, M.: 2000, Monetary Policy Rules And Macroeconomic Stability: Evidence And Some Theory, The Quarterly Journal of Economics 115(1), 147-180.

Cogley, T. and Sargent, T. J.: 2005, Drift and Volatilities: Monetary Policies and Outcomes in the Post WWII U.S, Review of Economic Dynamics 8(2), 262-302.

Dedola, L. and Neri, S.: 2007, What does a technology shock do? A VAR analysis with model-based sign restrictions, Journal of Monetary Economics 54(2), 512-549.

Di Pace, F. and Villa, S.: 2016, Factor complementarity and labour market dynamics, European Economic Review 82(C), 70-112. 
Erceg, C. J., Guerrieri, L. and Gust, C.: 2005, Can long-run restrictions identify technology shocks?, Journal of the European Economic Association 3(6), 1237-1278.

Fernald, J. G.: 2007, Trend breaks, long-run restrictions, and contractionary technology improvements, Journal of Monetary Economics 54(8), 2467-2485.

Fernald, J. G.: 2014, A quarterly, utilization-adjusted series on total factor productivity, Working Paper Series 2012-19, Federal Reserve Bank of San Francisco.

Fernald, J. G. and Wang, J. C.: 2016, Why has the cyclicality of productivity changed? what does it mean?, Annual Review of Economics 8(1), 465-496.

Fernandez-Villaverde, J. and Rubio-Ramirez, J. F.: 2008, How Structural Are Structural Parameters?, NBER Macroeconomics Annual 2007, Volume 22, NBER Chapters, National Bureau of Economic Research, Inc, pp. 83-137.

Fève, P. and Guay, A.: 2010, Identification of technology shocks in structural vars, Economic Journal 120(549), 1284-1318.

Fisher, J. D. M.: 2006, The dynamic effects of neutral and investment-specific technology shocks, Journal of Political Economy 114(3), 413-451.

Francis, N. and Ramey, V. A.: 2005, Is the technology-driven real business cycle hypothesis dead? shocks and aggregate fluctuations revisited, Journal of Monetary Economics 52(8), 1379-1399.

Francis, N. and Ramey, V. A.: 2009, Measures of per capita hours and their implications for the technology-hours debate, Journal of Money, Credit and Banking 41(6), 1071-1097.

Galí, J.: 1999, Technology, employment, and the business cycle: Do technology shocks explain aggregate fluctuations?, American Economic Review 89(1), 249-271.

Galí, J. and Gambetti, L.: 2009, On the Sources of Great Moderation, American Economic Journal: Macroeconomics 1(1), 26-57.

Galí, J., López-Salido, J. D. and Vallés, J.: 2003, Technology shocks and monetary policy: assessing the Fed's performance, Journal of Monetary Economics 50(4), 723-743.

Galí, J. and van Rens, T.: 2014, The vanishing procyclicality of labor productivity, Economics Working Papers 1062, University of Warwick.

Galvao, A., Giraitis, L., Kapetanios, G. and Petrova, K.: 2015, A Bayesian local likelihood method for modelling parameter time variation in DSGE models, Technical report, Mimeo. 
Giacomini, R. and Rossi, B.: 2016, Model comparisons in unstable environments, International Economic Review 57(2), 369-392.

Hicks, J. R.: 1932, The Theory of Wages, $1^{\text {st }}$ Edition, London: MacMillan.

Holly, S. and Petrella, I.: 2012, Factor demand linkages, technology shocks, and the business cycle, The Review of Economics and Statistics 94(4), 948-963.

Justiniano, A. and Primiceri, G. E.: 2008, The Time-Varying Volatility of Macroeconomic Fluctuations, American Economic Review 98(3), 604-41.

Katz, L. and Murphy, K.: 1992, Changes in relative wages, 1963-1987: Supply and demand factors, Quarterly Journal of Economics 107, 35-78.

King, R. G., Plosser, C. I. and Rebelo, S. T.: 1988, Production, growth and business cycles : I. the basic neoclassical model, Journal of Monetary Economics 21(2-3), 195-232.

Klump, R., McAdam, P. and Willman, A.: 2012, The Normalized Ces Production Function: Theory And Empirics, Journal of Economic Surveys 26(5), 769-799.

Krusell, P., Ohanian, L. E., Ríos-Rull, J.-V. and Violante, G. L.: 2000, Capital-Skill Complementarity and Inequality: A Macroeconomic Analysis, Econometrica 68(5), 1029-1054.

La Grandville, Olivier de.: 1989, In Quest of the Slutzky Diamond, American Economic Review 79, 468-481.

León-Ledesma, M. A., McAdam, P. and Willman, A.: 2010, Identifying the Elasticity of Substitution with Biased Technical Change, American Economic Review 100(4), 1330-1357.

León-Ledesma, M. A., McAdam, P. and Willman, A.: 2015, Production Technology Estimates and Balanced Growth, Oxford Bulletin of Economics and Statistics 77(1), 40-65.

León-Ledesma, M. A. and Satchi, M.: 2016, Appropriate Technology and Balanced Growth, Mimeo, School of Economics, University of Kent.

Lindé, J.: 2009, The effects of permanent technology shocks on hours: Can the RBC model fit the VAR evidence?, Journal of Economic Dynamics and Control 33(3), 597-613.

Miyagiwa, K. and Papageorgiou, C.: 2007, Endogenous aggregate elasticity of substitution, Journal of Economic Dynamics and Control 31(9), 2899-2919.

Nucci, F. and Riggi, M.: 2013, Performance pay and changes in U.S. labor market dynamics, Journal of Economic Dynamics and Control 37(12), 2796-2813. 
Papageorgiou, C. and Saam, M.: 2008, Two-level CES Production Technology in the Solow and Diamond Growth Models, Scandinavian Journal of Economics 110(1), 119-143.

Quah, D.: 1992, The relative importance of permanent and transitory components: Identification and some theoretical bounds, Econometrica 60(1), 107-18.

Ramey, V.: 2012, The impact of hours measures on the trend and cycle behavior of labor productivity, mimeo, UC San Diego.

Rebei, N.: 2014, What (really) accounts for the fall in hours after a technology shock?, Journal of Economic Dynamics and Control 45(C), 330-352.

Ríos-Rull, J.-V., Schorfheide, F., Fuentes-Albero, C., Kryshko, M. and Santaeulália-Llopis, R.: 2012, Methods versus Substance: Measuring the Effects of Technology Shocks on Hours, Journal of Monetary Economics 59(8), 826-846.

Rotemberg, J. J.: 2003, Stochastic Technical Progress, Smooth Trends, and nearly distinct Business Cycles, American Economic Review 93(5), 1543-1559.

Stiroh, K. J.: 2009, Volatility accounting: A production perspective on increased economic stability, Journal of the European Economic Association 7(4), 671-696.

Uhlig, H.: 2004, Do technology shocks lead to a fall in total hours worked?, Journal of the European Economic Association 2(2-3), 361-371.

Uzawa, H.: 1961, Neutral Inventions and the Stability of Growth Equilibrium, Review of Economic Studies 28, 117-124.

Wang, P. and Wen, Y.: 2011, Understanding the Effects of Technology Shocks, Review of Economic Dynamics 14(4), 705-724. 


\section{A Proof of Lemma 1}

We prove Lemma 1 for the first nesting corresponding to the Krusell et al. (2000) two-level CES, which we denote as $(X, U)$ nesting. The results for the second nesting easily follow through from these. We first need to use the following results:

$$
\begin{gathered}
\frac{\partial \pi_{X}}{\partial X}=\frac{\psi}{X} \pi_{X}\left(1-\pi_{X}\right), \\
\frac{\partial X}{\partial(1-n)}=\frac{1-\pi_{K}}{1-n} X, \\
\frac{\partial \pi_{K}}{\partial(1-n)}=-\theta \frac{\pi_{K}\left(1-\pi_{K}\right)}{1-n},
\end{gathered}
$$

which, since, for any variables $(z, q, s), \partial z / \partial q=(\partial z / \partial s)(\partial s / \partial q)$, immediately implies

$$
\frac{\partial \pi_{X}}{\partial(1-n)}=\psi \frac{\pi_{X}\left(1-\pi_{X}\right)\left(1-\pi_{K}\right)}{1-n} .
$$

With these results we can then calculate the partial derivative of $g=\frac{\pi_{K}}{\frac{1-\pi_{K}}{1-\pi_{X}}+\pi_{K}}$. After some tedious algebra, we can write this expression as:

$$
\left.\frac{\partial g}{\partial(1-n)}\right|_{X, U}=\frac{-\frac{\pi_{K}\left(1-\pi_{K}\right)}{(1-n)\left(1-\pi_{X}\right)}(\theta+\psi)}{\left[\frac{1-\pi_{K}}{1-\pi_{X}}+\pi_{K}\right]^{2}}
$$

Since $\frac{\partial \sigma}{\partial(1-n)}=\frac{\partial \sigma}{\partial g} \frac{\partial g}{\partial(1-n)}$ we can derive, again after some algebra, the expression:

$$
\left.\frac{\partial \sigma}{\partial(1-n)}\right|_{X, U}=-\Pi \frac{\left(\psi^{2}-\theta^{2}\right)}{[(1-\theta)+(\theta-\psi) g]^{2}},
$$

where $\Pi>0$ is a function of share parameters:

$$
\Pi=\frac{\pi_{K}\left(1-\pi_{K}\right)}{(1-n)\left(1-\pi_{X}\right)\left[\frac{1-\pi_{K}}{1-\pi_{X}}+\pi_{X}\right]^{2}}
$$

Given that $\Pi>0$ and that the denominator of (A.6) is positive, the effect of a change in $1-n$ will be positive if $\theta^{2}>\psi^{2}$. Hence, in the $(X, U)$ nesting, an increase in the share of skilled workers will increase aggregate $\sigma$ if $|\theta|>|\psi|$. Following the same logic, in the $(X, S)$ nesting, the effect will be positive as long as $|\theta|<|\psi|$. 